\title{
A Study of the Factors Affecting the Development of the Portfolio of Products of the Iranian Top Pharmaceutical Companies Using Promethee Method
}

\author{
Maryam Shahmohammadi \\ Engineering graduate student, Parand Branch, Islamic Azad University, Tehran, Iran \\ Ghassem Farajpour Khanaposhtani \\ Professor assistant, Department of Industrial Engineering, Parand Branch, Islamic Azad University, Tehran, Iran \\ *Corresponding Author Email: ghfarajpour44@gmail.com
}

Doi:10.5901/mjss.2016.v7n3s3p329

\begin{abstract}
It is very important to select new pharmaceutical products among the world's successful and best-selling products. What seems problematic in the development process of the portfolio of products is the analysis of potential and actual competitors and the rate of success of new products in achieving share from the pharmaceutical market. For this purpose, experts of pharmaceutical industry have been consulted in determining the factors affecting the development of the portfolio of products. The results of the data analysis suggest that the criterion "three-past-year average sales of pharmaceutical companies" is the most important.
\end{abstract}

Keywords: Development Of portfolio Of Pharmaceutical Products, Promethee

\section{Introduction}

Any organization is faced with certain goals, limitations, priorities, policies, opportunities and threats and problems, which it should take into consideration in its decision-making. An important subject in management and administration of organizations is decision-making, or put more accurately, assigning accurate decision-making tool to top managers of organizations to select the optimal or close-to-optimal portfolio of investment (Azar et al, 2012). Since it is very important to make optimal economic decisions in such an environment, one of the most influential decisions is about the portfolio of products. However, the capability of making the best possible decision (as the output) based on the past and present information and future predictions (as the input) is a complicated process.

Decision-making techniques has attracted researchers' attention since the early 1970s (Wu \& Zhang, (2011)) and optimization models have attracted mathematicians and industry practitioners since World War II. Since then, many people have tried to provide useful and optimal methods for planning and determining the portfolio of products.

The base and foundation of this planning to determine the portfolio of products is formed by designing similar products Jiao et al. have described this issue well. The modeling of the design of similar products was set forth by Zhihong et al. and was then presented by Jiao et al.

Today, despite the abundant attempts made for the optimal selection of portfolio of pharmaceutical products, no research has unfortunately been conducted yet about the effective criteria of developing this portfolio. Therefore, it seems necessary to investigate this category in order to attain more effectiveness in the selection of pharmaceutical products and achieve more competitive advantage in pharmaceutical products.

The first part of this study has dealt with a review of the literature and previous studies. The second part has dealt with the research methodology and the third part has determined the factors affecting the development of portfolio of pharmaceutical products besides making use of experts' viewpoints. Then, the implementation model was executed in Visual Promethee software, the results were analyzed and the output was confirmed. Finally, the results were analyzed and the conclusion was presented in the fourth part.

\section{A Review of the Theoretical Fundamentals and Literature}

We will explain the portfolio of products of pharmaceutical companies and multi-criteria decision-making in this part. 
Then, we will deal with some studies done for selection of the portfolio of products using multi-criteria decision-making methods.

\subsection{Portfolio of products of pharmaceutical companies}

Project portfolio refers to a set of projects in an economic unit and with the same strategic goals and common resources. The financial and physical resources of such projects are often quite limited and projects are competing with one another under the same management in order to attract these limited and rare resources. The process of evaluating, prioritizing and selecting the project is one of the most important and basic issues in project portfolio management. Portfolio management emphasizes that projects should be evaluated not only separately from one another, but also in the total set of projects, as they are hardly independent of one another by nature.

In other words, the portfolio or portfolio of projects refers to a set of projects done under the management of a given organization. The process of selecting the portfolio of projects is a periodical activity in which a set of projects is selected among the proposed projects in order to help achieve the organization's predetermined goals without the use of extra resources.

The pharmaceutical industry of the world has recently had a considerable growth in the amount of demand for generic (new) medicines in the pharmaceutical market of countries [Nassiri-Koopaei et al, 2014]. It seems that this status is considered the natural trend of the growth of generic medicines market and the pharmaceutical market of Iran is no exception to this rule.

Since there is a considerable difference between generic pharmaceutical industry and brand in terms of the process of product development, the factories manufacturing generic products can provide customers with products with a comparable quality to the reference brand in a shorter period of time and with much lower cost and price and can considerably reduce the costs of the health system and household portfolio.

Unlike brand industry in which the medicine's manufacturing company is in charge of the entire stages ranging from the discovery of molecule to the sales of the product in the market as well as all clinical trials, in generic industry the manufacturing company should only prove that the manufactured product of that company is like the product of the reference brand in terms of quality, bioequivalence studies, effectiveness and efficiency, and that the company is not responsible for performing clinical trials and the stages of discovery, research and development of primary molecule, which considerably reduces the cost and time of developing a new product. Therefore, the stage of new generic product selection for the product development process is also quite different from brand industry.

The process of new (generic) product selection which is done among the successful and best-selling brand products is considered an important process, because due to the limitation of capital resources, the policy makers and managers of this industry stress the optimal allocation of resources to the projects of manufacturing new and efficient medicines which have priority in terms of profitability and health promotion in the society.

Considering cases like this, which create problems in the process of producing selected products, it is necessary to analyze the competitors that present new products and to develop the portfolio of products with regard to the figures.

\subsection{Multi-criteria decision-making}

Multi-criteria decision-making is an important research area in decision-making science and is widely used in many fields such as economy and management. Several criteria of assessment rather than only one optimality assessment criterion are used in this type of decision-making. Decision-making models are of two main types: multi-objective decision-making and multi-attribute decision-making. Multi-objective models are used for design, whereas multi-attribute models are used to select the top alternative (Asgharpour, (2010).

In multi-objective decision-making models, several objectives are simultaneously pursued for optimization and the assessment scale foe each objective may be different from that for other objectives. However, multi-attribute decisionmaking models deal with selecting or ranking one alternative from among several alternatives evacuated with nalternatives.

Many models for selection of the portfolio of products have been presented so far, the similarity of which is tendency to multi-criteria models (Mohaghar \& Mostafavi (2007)). Considering the topic studied in this research, the decision-making in this research is multi-criteria decision-making. 


\subsection{Previous Studies}

Nowadays, there is an increasing need for the development of new markets and products (Cooper \& Kleinschmidt, (1993)), and the companies that are active in pharmaceutical industry arena need the market development strategy in order to create sustainable competitive advantage. Therefore, the marketers of this arena should focus more on the development of their own marketing models which can help them understand, interpret and predict the events and market performance (Ghasemi et al, 2009).

The increasing competition in business makes companies compete with one another at the national and international levels in order to survive the market (Sinaei \& Rashidizadeh, (2010)). Today, achieving a top competitive position and conquering the competitors or following the competitive goals are among the main concerns of companies, especially those active in pharmaceutical products. However, what financial and non-financial consequences the achievement of a top competitive position can have for these companies is a contested issue. Making attempts to increase the market share, make customers loyal, increase the quality of the product, reduce the cost price and improve and establish the financial position of companies amounts to companies' trying to promote the competitive position and achieve a better competitive position in the competitive environment of the present market.

Competitiveness can generally be regarded as capabilities that a business, industry, region or country has and can maintain in order to create a high return rate at the international competition level. In other words, competitiveness refers to the ability to increase market share, get profit, increase the added value and stay in the international competition arena for a long period of time (Man et al, 2002).

Another controversial issue is organizational strategy. Organizational strategy refers to making the optimal and complete use of all capacities in order to achieve the prospects and main objectives of organizations by taking advantage of different options and tools.

As one of the main inputs of medical cares, medicine has an outstanding feature that distinguishes its position from that of other sectors (Kebriaeezadeh et al, 2010). The pharmaceutical costs and its other related costs in Iran and many other developing countries constitute about $30 \%$ of the total costs of medical cares and approximately $50 \%$ of the total costs of outpatient health and medical cares.

We have dealt in this research with the detection and prioritization of the key factors affecting competition in pharmaceutical industry of the country. The pharmaceutical industry has changed a lot during the past ten years (Munos, (2009)) and most of the changes have occurred due to research and development activities [12.40], uncertainty in the process of medicine development, shortage of new products (Engelhardt \& Garrett, (2008)), too fast mergers (Schweizer, (2005)) fast development of public markets (Karhu \& Yla-Kojola, (2010)), and finally an increase in global competition and technology development (McAdam \& Barron, (2002)).

Considering the increasing competition in medicines, the performance of pharmaceutical companies should be accurate, fast and futuristic. Moreover, due to the intensely competitive environment, it is very important to identify the factors influencing competition in pharmaceutical industry in the international market (Kesič, (2009)). The pharmaceutical industry of Iran has had a growth of over 28.38 percent during the last 10 years. The medicines produced in Iran during these years have cost 1.69 billion dollars (Shabaninejad et al, 2014).

It should be noted that based on the existing evidence and according to the investigations approving of the lack of a document or report in previous studies to evaluate and rank companies with favorable parameters, it seems that this research has been designed and documented for this purpose for the first time. Although pharmaceutical companies periodically analyze their competitors and their changes of the portfolio, their reports are not definitely publicized. No report about this was actually observed in different websites such as IRANDOC and CIVILIKA.

\section{Research Methodology}

The present research is an applied research in terms of purpose, a qualitative one in terms of nature and research method and a descriptive-survey and causal research in type.

The research population includes 374 medicine exporting and importing companies in Iran, the figures and information needed by these companies were obtained from the official statistics of the Ministry of Health, Treatment and Medical Education available in the website of this ministry during the recent-ten-year interval (between 2004 and 2013). For data collection, the librarian method and field method were used respectively for the theoretical fundamentals and extraction of the criteria factors, and experts' views were used for confirmation of the factors and criteria of the research model, and for the ranking of the factors and criteria.

The members of the team of experts were 20 managers, all with PhD degrees, from the Organization of Food and 
Drug and the Ministry of Health, Treatment and Medical Education with at least five years of experience in the Pharmaceutical Industry of the country.

Due to the extensive statistical population and the problems of entering data to the software, the sample size can be selected from the population in one of the following two states:

A: 52 top companies which have $80 \%$ of the sales share from the pharmaceutical market in 2013.

B: 20 top companies which have $50 \%$ of the sales share from the pharmaceutical market in 2013.

After frequent examinations, consulting the experts and ranking the companies in terms of sales share in 2013, the second state was eventually selected. Thus, 20 top pharmaceutical companies of the country, ranked in terms of sales share in 2013, are as follow:

Cobel Daru, Behestan Daru, Darupakhsh, Eksir, Farabi, Abidi, Tehran Shimi, Alborz Daru, Dana, Actover, Jaber ebn Hayan, Shafayab Gostar, Abureihan, Sina Daru, K.B.C., Sobhan Daru, Caspian Tamin, Cinnagen, Osveh, Iran Hormone.

The data analysis method used in the research to measure frequencies and averages is correlation and regression at the same time, and Promethee Technique and Visual Promethee Software have been used foe the comparison of the companies in terms of the criteria of success, and Shannon Entropy Method has been used for weighting the criteria. Figure 1 shows the stages of the research execution.

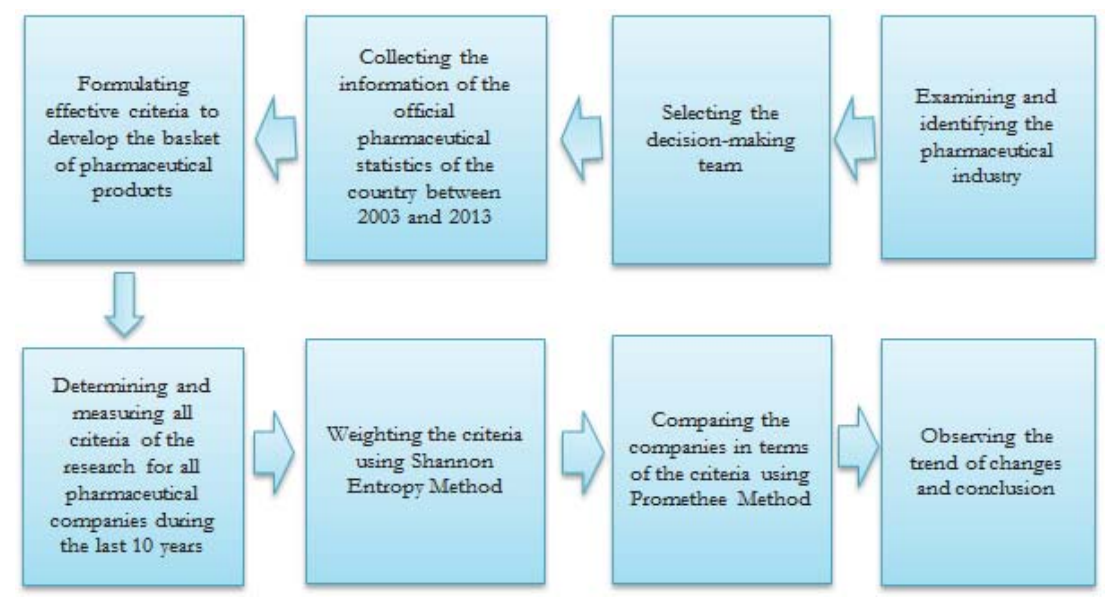

Figure 1: stages of the research execution

\subsection{Entropy Method}

For multi-criteria decision-makings, the criterion weight is an important factor for determining the relative importance of criteria, and Shannon Entropy Method is one of the methods of determining weights. The term "entropy" meaning disorder, was first posed by Rudolf Clausius in 1865 in the field of thermodynamics and by Claude Shannon in 1978 in the ICT field (Zhang, et al, 2010). After Shannon expressed the entropy of information in his article "Mathematical Theory of Communication", it was extensively used afterwards in different fields such as engineering, management and so on (Wu \& Zhang, (2011)). Shannon Entropy Method is an appropriate method for measuring the relative importance of attributes and transferring the intrinsic value of data to the decision-maker (Wang \& Lee, (2009)). Entropy is a good tool for evaluating the weight of the criteria of a decision problem which is defined as a complete matrix (Shanian \& Savadogo, (2006)). This method calculates the weights of each criterion in terms of distribution of the criterion values. The more distributed the values of a criterion is, the more important that cri will be (Zhao et al, 2010). If we have a decision matrix with the degree of $m \times n$, such that $m$ represents the number of alternatives, shown by $A 1$ to Am, and that $\mathrm{n}$ represents the number of criteria, displayed by $\mathrm{C} 1$ to $\mathrm{Cn}$, we use Entropy Method to calculate the weight of the criteria in the following way ((Wang et al, 2008), (Zhi-hong et al, 2006)): 


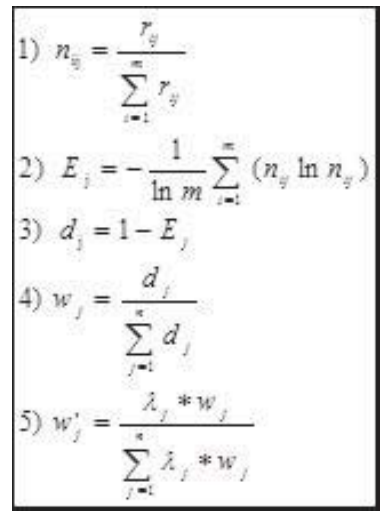

Figure 2: formulas of computing the weight of criteria using Entropy Method

a- At first, the matrix is normalized using this formula (figure 2). Based on this formula, the value of elements of each matrix is divided by the sum of the column.

b- Computing the entropy value: $\mathrm{Ej}$, (In) logarithm is based on p-value.

c- Computing the degree of deviation: $d$

d- Computing the criteria weight: $w$

e- Adjusting the criteria weight

\subsection{Promethee Method}

Promethee Method is one of the multi-criteria decision-making methods described in the following way. Suppose that $A$ is a set of alternatives among which one alternative is to be selected. Assuming that there is k effective criteria in decisionmaking, foe each alternative $\mathrm{Aa}$, the value of $\mathrm{fj}$ (a) represents the $\mathrm{j}$-th criterion value in alternative $\mathrm{a}$. Ranking is done at three stages [16]:

First stage - creating generalized criterion: the Pj preference function is given to each one of $j$ criteria. The value of $\operatorname{Pj}(a, b)$ is computed for each alternative pair. This value ranges from zero to one. If the relation $\mathrm{fj}(\mathrm{a})=\mathrm{fj}(\mathrm{b})$ exists, the value of $\mathrm{Pj}(\mathrm{a}, \mathrm{b})$ becomes zero and when $\mathrm{fj}(\mathrm{a})-\mathrm{fj}(\mathrm{b})$ increases, this value also increases. When the difference becomes high enough, the value of $\mathrm{Pj}(\mathrm{a}, \mathrm{b})$ also becomes 1 . Different forms can be supposed for $\mathrm{Pj}$ function, which depends on modeling the jth criterion. As shown in Table 1, Promethee Method proposes six generalized criteria to decision-makers for preference function (Pourreza et al, 2014).

Table 1: description of the generalized criteria

\begin{tabular}{|c|c|c|}
\hline description & relation & Criterion name \\
\hline If the two alternatives have the same score, there will be no difference. & $P(d)= \begin{cases}0 & d=0 \\
1 & d>0\end{cases}$ & $\begin{array}{c}\text { Usual } \\
\text { Preference } \\
\end{array}$ \\
\hline There will be no difference until the difference of the scores of the two alternatives is less than q. & $\mathrm{P}(\mathrm{d})=\left\{\begin{array}{l}0 \mathrm{~d} \leq \mathrm{q} \\
1 \mathrm{~d}>q\end{array}\right.$ & $\begin{array}{l}\text { U-shape } \\
\text { preference }\end{array}$ \\
\hline $\begin{array}{l}\text { With a change of scores in the distance of zero and } p \text {, the priority will change in linear form. If the } \\
\text { difference is more than } p \text {, the considered alternative has complete priority. }\end{array}$ & \multirow{3}{*}{$\begin{array}{c}\mathrm{P}(\mathrm{d})=\left\{\begin{array}{l}\frac{\mathrm{d}}{\mathrm{p}} \mathrm{d} \leq \mathrm{p} \\
1 \mathrm{~d}>p\end{array}\right. \\
=\left\{\begin{array}{r}1 / 2 \mathrm{~d} \leq \mathrm{q}< \\
1 \mathrm{~d}>p\end{array}\right. \\
=\left\{\begin{array}{r}\mathrm{P}(\mathrm{d}) \\
0 \mathrm{~d} \leq \mathrm{q}\end{array}\right. \\
=\left\{\begin{array}{r}\mathrm{d}-\mathrm{q} \\
\mathrm{p}-\mathrm{q} \\
1 \mathrm{~d}>\mathrm{d} \leq p\end{array}\right.\end{array}$} & $\begin{array}{l}\text { Linear } \\
\text { Preference }\end{array}$ \\
\hline $\begin{array}{l}\text { If the difference of scores is less than } q \text {, there will be no difference. If the difference is between the } \\
\text { values of } p \text { and } q \text {, there will be a comparative advantage, and if the rate of difference is more than } p \text {, } \\
\text { there will be complete priority. }\end{array}$ & & $\begin{array}{l}\text { Level } \\
\text { Preference }\end{array}$ \\
\hline $\begin{array}{l}\text { If the difference of scores of the two alternatives is less than } q \text {, there will be no difference. With a } \\
\text { change of scores within the distance of } p \text { to } q \text {, the priority rate will change in linear form. If the } \\
\text { distance rate is more than } p \text {, there is complete priority. }\end{array}$ & & $\begin{array}{l}\text { V-shape } \\
\text { Preference }\end{array}$ \\
\hline $\begin{array}{l}\text { With the difference among the scores of alternatives, the priority rate will increase according to the } \\
\text { relation. }\end{array}$ & $P(d)=1-e^{-\frac{d^{2}}{2 \delta^{2}}}$ & $\begin{array}{l}\text { Gaussian } \\
\text { preference }\end{array}$ \\
\hline
\end{tabular}


The second stage - determining the relation of ranking among the alternatives: the total rate of priority $\pi(a, b)$ for each alternative $a$ is computed over the alternative $b$. the more the amount of $\pi(a, b)$, the more preferable the alternative a will be.m $(a, b)$ is computed in the following way:

$$
\pi(a, b)=\sum_{j=1}^{k} w j p j(a, b),\left(\sum_{j=1}^{k} w j=1\right)
$$

The third stage - evaluating the ranking for determining the final answer $\pi(a, b)$ : this represents the priority degree of alternative an in ratio to alternative $b$. the output flow is computed in order to determine the total preference power of alternative an over the other alternatives:

Positive ranking flow or output flow

$$
\text { (a) }=\frac{1}{n-1} \sum_{x \in A} \pi(a, x) \quad \varphi+
$$

This flow shows how preferable alternative is in ratio to other alternatives. This flow is actually the power of alternative $a$. The largest $\varphi^{+}$(a) means the best alternative. The preference rate of other alternatives over alternative a, which is called the input flow, is computed in the following way:

Negative ranking flow or the input flow

$$
\frac{1}{n-1} \sum_{x \in A} \pi(x, a) \quad(\mathrm{a})=\varphi-
$$

This flow shows how preferable other alternatives are over alternative a. this flow actually represents weakness of alternative a. The smallest $\varphi$-(a) shows the best alternative. Therefore, one can do a detailed ranking by separately examining the two flows of $\varphi+$ and $\varphi$ - (ranking of PROMETHEE I). For the complete ranking of alternatives, the net flow of ranking should be defined for each alternative (ranking of PROMETHEE II):

$$
\mathrm{a}(-)-\varphi \mathrm{a} \varphi+((\mathrm{a})=\varphi
$$

This flow is the result of the balance of positive and negative ranking flows. The higher net flow shows the higher alternative.

Among the important advantages of Promethee Method are simplicity, clarity and reliability of its results. This method can do the process of evaluation on a limited set of limited alternatives in the form of a detailed or complete ranking. The clear effect of each criterion and its weight on the answers, the high performance and efficiency of algorithm in this method despite its simplicity and its foundation based on the importance of the performance difference between two answers - distinguish this method from Analytic Hierarchy Approach (Cooper \& Kleinschmidt, (1993)).

\section{Findings}

\subsection{Definition of the criteria}

The present research has been done based on the ten-year sales statistics of the active pharmaceutical companies in the country between 2004 and 2013 and has regarded 10 variables as the factors affecting the development of the portfolio of products of pharmaceutical companies after the studies and investigations, as observed in the conceptual model shown in Figure 3.

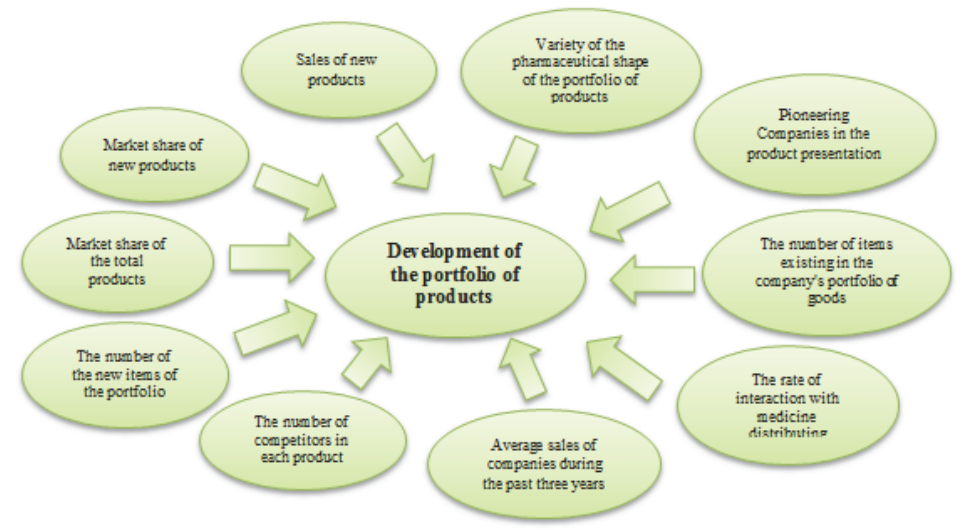

Figure 3: factors affecting the development of portfolio of products of pharmaceutical companies 
In this study, the experts included 20 medical and health sector managers with at least 25 years of presence in the industry that questionnaires have been distributed among them. About the validity and reliability of the distributed questionnaire, The Cronbach's alpha coefficient method and SPSS software were used and the Cronbach's alpha coefficient was estimated to be 0.868 . The formula for calculating Cronbach's alpha coefficient is as follows: $\mathrm{K}$ is the number of questions in the questionnaire, $\mathrm{s}^{2}$ is the total variance of questions and $\mathrm{si}^{2}$ is the variance of each question.

$$
\alpha=\frac{k}{k-1}\left(1-\frac{\sum_{i=1}^{k} s_{i}^{2}}{s^{2}}\right)
$$

\subsection{Computing the criteria weight using Entropy Method}

Due to the importance and advantages of Entropy Method, this method is used for computing the criteria weights. Different stages of this method include computation of Ej, and dj has been done using Excel Software and has been computed using the formula of WI values (Table 2). The adjusted weights of wj were finally obtained via the subjective judgments of experts, as shown in Table 3.

Table 2: weights according to experts' views

\begin{tabular}{|l|c|c|}
\hline Criterion & Rank & Weight \\
\hline Variety of shape & 1 & 2 \\
\hline New portfolio & 9 & 16 \\
\hline Total portfolio & 6 & 10 \\
\hline pioneer & 4 & 7 \\
\hline Number of distributions & 3 & 7 \\
\hline Market share & 5 & 8 \\
\hline Average of 3-year sales & 10 & 22 \\
\hline New market share & 7 & 12 \\
\hline New sales & 8 & 13 \\
\hline competitors & 2 & 3 \\
\hline
\end{tabular}

Table 3: adjusted weights

\begin{tabular}{|l|c|c|}
\hline Criterion & Rank & Weight \\
\hline Variety of shape & 1 & 0.011 \\
\hline New portfolio & 7 & 0.11 \\
\hline Total portfolio & 5 & 0.099 \\
\hline pioneer & 4 & 0.061 \\
\hline Number of distributions & 3 & 0.037 \\
\hline Market share & 6 & 0.106 \\
\hline Average of 3-year sales & 10 & 0.29 \\
\hline New market share & 8 & 0.127 \\
\hline New sales & 9 & 0.131 \\
\hline competitors & 2 & 0.027 \\
\hline
\end{tabular}

\subsection{Data collection and decision matrix}

In this study, after determining the criteria of the factors affecting the development of the pharmaceutical companies' portfolio of products, a multi-criteria decision-making model based on Promethee Method has been designed.

After determining the criteria weights, Promethee method has been used to help rank the companies and determine their priority based on the ten-fold criteria. Visual Promethee Software has been utilized for this purpose. At the beginning, the number of alternatives and then criteria are determined. At the next stage, the values of the decision matrix are entered into the software.

Therefore, decision matrix is formed based on the ten criteria of decision-making and 20 top pharmaceutical companies of the country ( $\mathrm{C} 01$ to $\mathrm{C} 020$ or A1 to A20 in decision matrix), as shown in Table 4. 
Table 4: Decision-making matrix

\begin{tabular}{|c|c|c|c|c|c|c|c|c|c|c|}
\hline Criteria/ companies & 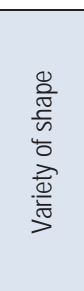 & 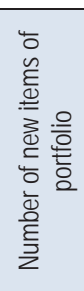 & 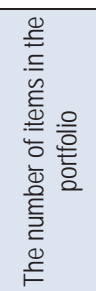 & 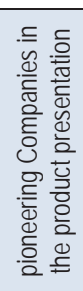 & 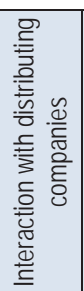 & 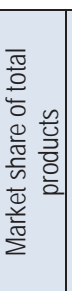 & 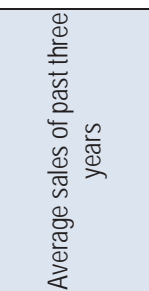 & 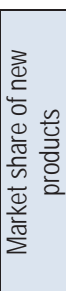 & 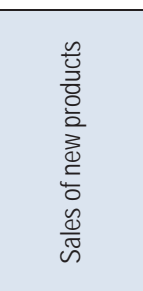 & 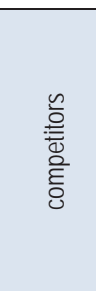 \\
\hline C01 & 106,00 & 142,00 & 596,00 & 61,00 & 62,00 & 0,42 & 11748742,51 & 0,05 & 1153959,38 & 1271,00 \\
\hline $\mathrm{Co2}$ & 122,00 & 232,00 & 1071,00 & 79,00 & 52,00 & 0,30 & 8449642,92 & 0,03 & 752626,11 & 2901,00 \\
\hline $\mathrm{Co3}$ & 158,00 & 185,00 & 1987,00 & 33,00 & 25,00 & 0,48 & 11168683,74 & 0,01 & 258193,95 & 8134,00 \\
\hline Co4 & 101,00 & 147,00 & 1169,00 & 40,00 & 33,00 & 0,44 & 10591403,75 & 0,03 & 792195,23 & 5868,00 \\
\hline $\mathrm{Co5}$ & 53,00 & 90,00 & 565,00 & 17,00 & 69,00 & 0,39 & 8823186,56 & 0,00 & 101711,16 & 2621,00 \\
\hline Co6 & 67,00 & 153,00 & 1018,00 & 42,00 & 54,00 & 0,16 & 4104432,51 & 0,01 & 282415,34 & 5589,00 \\
\hline Co7 & 87,00 & 117,00 & 910,00 & 15,00 & 65,00 & 0,24 & 6280372,52 & 0,01 & 363568,11 & 4991,00 \\
\hline C08 & 91,00 & 137,00 & 728,00 & 23,00 & 67,00 & 0,21 & 5449201,30 & 0,01 & 308938,01 & 257,00 \\
\hline Co9 & 68,00 & 107,00 & 518,00 & 33,00 & 80,00 & 0,18 & 4731814,34 & 0,01 & 178095,14 & 1709,00 \\
\hline Co10 & 70,00 & 102,00 & 416,00 & 10,00 & 39,00 & 0,10 & 2523334,74 & 0,01 & 711030,95 & 2611,00 \\
\hline Co11 & 112,00 & 124,00 & 769,00 & 27,00 & 71,00 & 0,34 & 7962676,97 & 0,01 & 309649,12 & 2091,00 \\
\hline Co12 & 107,00 & 260,00 & 958,00 & 106,00 & 59,00 & 0,26 & 7270815,38 & 0,03 & 702979,34 & 687,00 \\
\hline Co13 & 71,00 & 164,00 & 1064,00 & 40,00 & 27,00 & 0,15 & 3897604,97 & 0,00 & 84990,82 & 3130,00 \\
\hline Co14 & 4,00 & 2,00 & 6,00 & 0,00 & 6,00 & 0,00 & 3927,55 & 0,00 & 1235,42 & 318,00 \\
\hline Co15 & 49,00 & 96,00 & 207,00 & 12,00 & 49,00 & 0,11 & 2703056,27 & 0,03 & 779386,27 & 762,00 \\
\hline Co16 & 55,00 & 112,00 & 968,00 & 17,00 & 66,00 & 0,16 & 3982109,54 & 0,00 & 79520,00 & 5218,00 \\
\hline Co17 & 64,00 & 58,00 & 758,00 & 8,00 & 42,00 & 0,14 & 3655165,87 & 0,00 & 42583,49 & 211,00 \\
\hline Co18 & 16,00 & 7,00 & 22,00 & 0,00 & 10,00 & 0,07 & 2157333,20 & 0,01 & 208732,20 & 76,00 \\
\hline C019 & 60,00 & 112,00 & 645,00 & 45,00 & 63,00 & 0,15 & 4240322,28 & 0,02 & 534822,74 & 3030,00 \\
\hline Co20 & 30,00 & 76,00 & 578,00 & 20,00 & 45,00 & 0,11 & 2894435,85 & 0,00 & 78718,03 & 2064,00 \\
\hline
\end{tabular}

\subsection{Prioritization of the alternatives using Promethee Method}

In this part of the research, we apply the Visual Promethee Software and do the computations, and thus obtain the required outputs or ranking of 20 pharmaceutical companies including both manufacturing and importing companies as shown in the following:

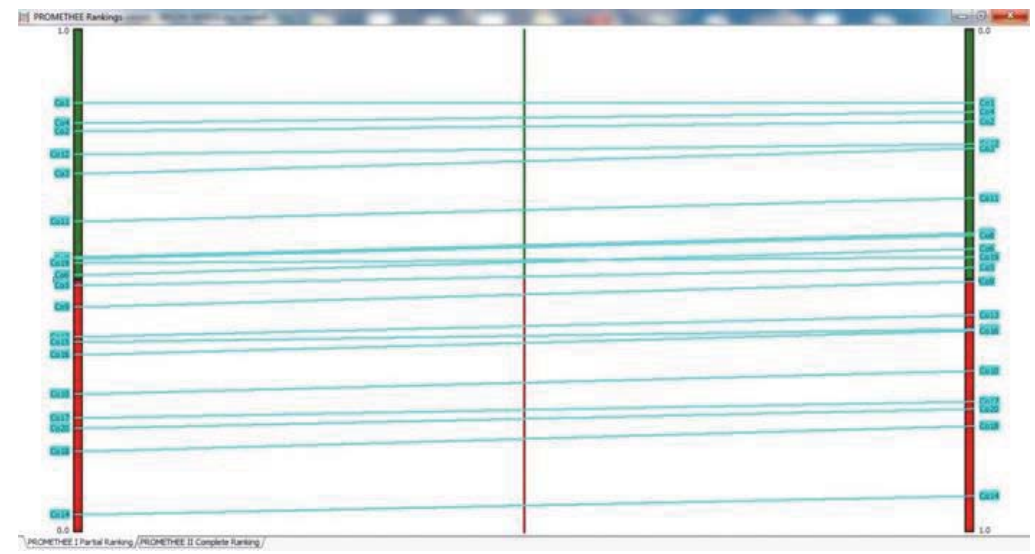

Figure 4: Detailed ranking using Promethee Method 


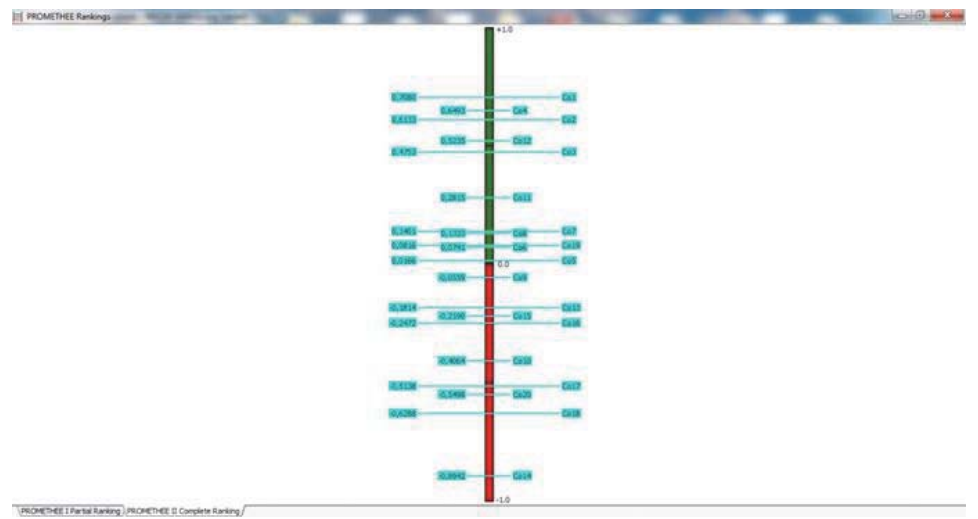

Figure 5: Complete Ranking using Promethee Method

\begin{tabular}{|c|c|c|c|c|}
\hline & action & Phi & Phit & Phi- \\
\hline 1 & $\mathrm{CO}_{1}$ & 0,7030 & 0,8540 & 0,1460 \\
\hline 2 & Co4 & 0,6493 & 0,8130 & 0,1637 \\
\hline 3 & $\mathrm{CO} 2$ & 0,6133 & 0,7966 & 0,1833 \\
\hline 4 & Co12 & 0,5235 & 0,7517 & 0,2282 \\
\hline 5 & $\cos 3$ & 0,4753 & 0,7126 & 0,2374 \\
\hline 6 & Co11 & 0,2815 & 0,6174 & 0,3358 \\
\hline 7 & $\mathrm{Co} 7$ & 0,1401 & 0,5466 & 0,4066 \\
\hline 8 & $\cos$ & 0,1333 & 0,5433 & 0,4099 \\
\hline 9 & Co19 & 0,0816 & 0,5351 & 0,4535 \\
\hline 10 & Co6 & 0,0741 & 0,5108 & 0,4368 \\
\hline 11 & $\cos$ & 0,0166 & 0,4900 & 0,4734 \\
\hline 12 & $\cos$ & $-0,0559$ & 0,4471 & 0,5029 \\
\hline 13 & Co13 & $-0,1814$ & 0,3882 & 0,5696 \\
\hline 14 & Co15 & $-0,2190$ & 0,3777 & 0,5967 \\
\hline 15 & Co16 & $-0,2472$ & 0,3524 & 0,5996 \\
\hline 16 & Co10 & $-0,4064$ & 0,2734 & 0,6798 \\
\hline 17 & Co17 & $-0,5138$ & 0,2264 & 0,7402 \\
\hline 18 & Co20 & $-0,5498$ & 0,2056 & 0,7554 \\
\hline 19 & Co18 & $-0,6288$ & 0,1606 & 0,7894 \\
\hline 20 & Co14 & $-0,8942$ & 0,0346 & 0,9288 \\
\hline
\end{tabular}

Figure 6: The Promethee Flow Table

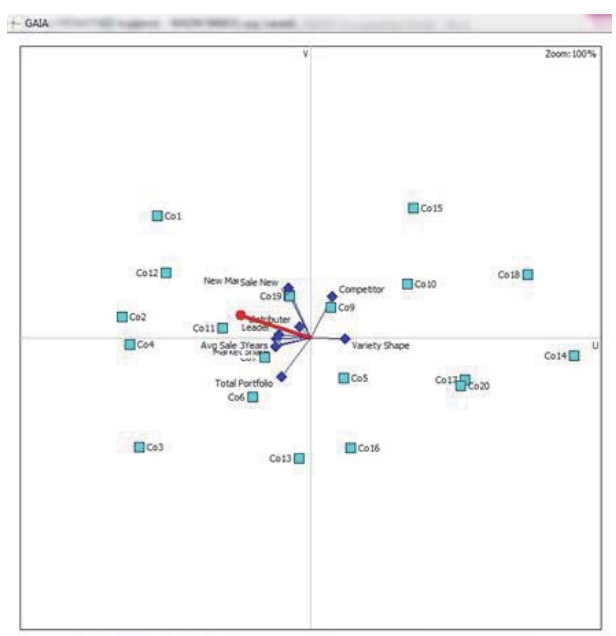

Figure 7: Gaia Visual Module 
With regard to the input values in the software, as shown in figure 6 , the highest rank belongs to Col Company with net $\varphi$ of 0.7080 . (net $\varphi$ shows the software preference in choosing the options and the higher its value is, the better the preference sign will be), and the lowest rank belongs to Co14 with net $\varphi$ of 0.8942 .

In figure 7, Gaia Visual Module, the line orientation with the circle end shows movement toward the best preference (Co1), and alternatives which are in the opposite direction of the best case show the worst preference. Using this figure, one can see that $\mathrm{C} 01, \mathrm{C}_{0} 4, \mathrm{C} 02$ and $\mathrm{C}_{012}$ have a high preference due to their having positive net $\varphi$, while C014, C017, C018 and Co20 have the lowest preference as they have negative net $\varphi$.

\subsection{Validation of the model}

The review done by industry experts on the obtained results showed that the ranking of the companies using the proposed model is confirmed by them, but determining the parameters of evaluation in ranking the companies is of great importance. For example, when the parameter of the medicine manufacturing or importing company's activity history is one of the ranking parameters, companies with low experience of manufacturing and high volume of sales, without many competitors, get a good rank during the recent years and they can be called newly emerging competitors.

Therefore, considering the variety of influential parameters in ranking, it can be said that the above-mentioned model is dependent on the parameters of evaluation and determining the parameters of evaluation is a separate topic from the research issue.

\section{Conclusion}

We tried in this research to identify the criteria affecting the development of the portfolio of products of Iran's top pharmaceutical companies by examining the pharmaceutical industry of the country and using the views and experiences of experts from this industry, and rank the pharmaceutical companies including the manufacturing and importing ones using the multi-criteria decision-making method of Promethee by weighting the criteria using Shannon Entropy Method.

The results of analyzing the data suggest that the criterion "the average sales of pharmaceutical companies during the last three years" has the most importance, and the criterion "variety of medicine's shape" has the least importance.

Researchers can investigate the impact of different criteria on the pharmaceutical companies' portfolio of products in future by studying other performance indicators of companies, especially the important indicators in cases of companies' profit and loss such as net profit, the value of assets, the number of human resources, the number of investments, shareholders' contribution and bank debt,

\section{References}

Cooper, R, G. AND Kleinschmidt, E.J.: (1993), Major new products: what distinguishes the winners in the chemical industry?" Journal of product Innovation Management, Vol.10 No.2, pp.90-111.

Engelhardt HT, Garrett JR: (2008), "Innovation and the Pharmaceutical Industry: Critical Reflections on the Virtues of Profit." United States: $M$ \& M Scrivener Press.

Ghasemi, H., Alipour, A, Torabi, S.A.A.: (2009), "A Dynamic Model for Promotion of Iranian Pharmaceutical and Biological Enterprises." Archives of Razi Institute, Vol. 64, No. 2 121-128

Hsieh PH, Mishra CS, Gobeli DH: (2003), "The return on R\&D versus capital expenditures in pharmaceutical and chemical industries." IEEE Trans Eng Manag, 50:141-150.

Karhu A, Yla-Kojola AM: (2010), "Internationalization of pharmaceutical retail sector: growth opportunities in emerging markets." Int J Bus Excel, 3:363-382.

Kebriaeezadeh, Abbas, Nassiri Koopaei, Nasser, Abdollahiasl, Akbar, Nikfar, Shekoufeh and Nafiseh Mohamadi: (2013), "Trend analysis of the pharmaceutical market in Iran; 1997-2010; policy implications for developing countries". DARU Journal of Pharmaceutical Sciences, 21:52

Kesič D: (2009), "Strategic analysis of the world pharmaceutical industry."Management, 14:59-76.

Man, Thomas W.Y, Lau, T. and Chan K.F. (2002), "The Competitiveness of Small and Medium Enterprises A Conceptualization with Focus on Entrepreneurial Competencies." Journal of Business Venturing, 17:123-142.

McAdam R, Barron N: (2002), "The role of quality management in pharmaceutical development: clinical trials analysis." Int J Health Care Qual Assur, 15:106-123.

Munos B: (2009), "Lessons from 60 years of pharmaceutical innovation. Nat Rev Drug Discov 8:959-968.

Nassiri-Koopaei Nasser, Majdzadeh Reza, Kebriaeezadeh Abbas, Rashidian Arash, Tabatabai Yazdi Mojtaba, Nedjat Saharnaz and Shekoufeh Nikfar: (2014), "Commercialization of biopharmaceutical knowledge in Iran; challenges and solutions. "DARU Journal of Pharmaceutical Sciences, 22:29 
Rasekh HR, Mehralian GH, Vatankhah-Mohammadabadi AA: (2012), "Situation analysis of R \& D activities: an empirical study in Iranian pharmaceutical companies. Iran J Pharm Res, 11:1013-1025.

Schweizer L: (2005), "Organizational integration of acquired biotechnology companies into pharmaceutical companies: the need for a hybrid approach." Acad Manage J, 48:1051-1074.

Shabaninejad Hosein, Mehralian Gholamhossein, Rashidian Arash, Baratimarnani Ahmad and Rasekh HR: (2014), "Identifying and prioritizing industry-level competitiveness factors: evidence from pharmaceutical market." DARU Journal of Pharmaceutical Sciences, 22:35

Shanian, A. O. Savadogo, (2006), "A material selection model based on the concept of multiple attribute decision making Materials and Design," 27 (329-337).

Tzeng, G. H. \& Huang, J. J., (2011). "Multiple Attribute Decision Making: Methods and Applications," London, CRC Press.

Wang, J.-J. Z.Chun-Fa, J.You-Yin, Z.Guo-Zhong, (2008), "Using the fuzzy multi-criteria model to select the optimal cool storage system for air conditioning," Energy and Buildings 40 (2059-2066).

Wang, T.C. and Lee, H.D., (2009), "Developing a fuzzy TOPSIS approach based on subjective weights and objective weights,"Expert Systems with Applications, 36, pp. 8980-8985hu.

Wu, J.Z. and Zhang, Q., (2011), "Multi-criteria decision making method based on intuitionistic fuzzy weighted entropy,"Expert Systems with Applications, 38, pp. 916-922.

Zhang, H., Gu, C.L., Gu, L.W. and Zhang, Y., (2010), "The evaluation of tourism destination competitiveness by TOPSIS \& information entropy - A case in the Yangtze River Delta of China," Tourism Management, 32(2), pp. 443-451.

Zhao, X., Qi, Q. and Li, R., (2010), "The establishment and application of fuzzy comprehensive model with weight based on entropy technology for air quality assessment," Symposium on Security Detection and Information Processing, 7, pp. 217-222, available from: www.sciencedirect.com

Zhi-hong.Z, Y. Yi, S. Jing-nan, (2006), "Entropy method for determination of weight of evaluating in fuzzy synthetic evaluation for water quality assessment," Journal fo environ mental science, Vol. 18 No. 5, pp 1020-1023.

Hasan Ali Sinaei; Fatemeh Rashidizadeh (2010). A Study of the Relationship between Market Share Changes and Valuation of the Revenues and Future Growth Opportunities of Companies. Accounting and Audit Investigations, Series 17, NO. 59, pp 31-46.

Saeid Falahpour; Hossein Safari; Nader Emrani (2014). Portfolio Selection using the combination of the planning method of Logarithm and Promethee fuzzy preference, Financial Management Strategy, 2nd year, NO. 5, pp 103-120.

Sohrab Pourreza, Hossein Akbaripour, Mohammad Reza Amin Nasseri (2014). /developing Artificial Neural Network in order to select the Portfolio of products in organizations. Special Journal of Industries Engineering, series 48, NO. 1, pp. 51-65.

Adel Azar, Najmeh Ramoz, Ali Reza Atefat Dust (2012). The Application of the estimation method of non-preferred set in the selection of the optimal portfolio, Financial Studies, 14(2), 14-1.

Ali Mohaghar, Amir Mostafavi (2007). Presenting a Model for Selection of Project Group Using the Fuzzy Approach, Quarterly Journal of Modarres, series 11, NO. 3.

Mohammad Javad Asgharpour (2010). Multi-criteria Decision-makings. Tehran: Tehran University Press, pp 191-200. 